\title{
Synthesis of high-energy-density $\operatorname{Pr}_{2} \mathrm{Fe}_{14-x} \mathrm{Co}_{x} \mathrm{~B}, x \leqslant 3$, magnets for practical applications ${ }^{\dagger}$
}

\author{
S HALDAR, S RAM*, P RAMACHANDRARAO and H D BANERJEE** \\ National Metallurgical Laboratory, Jamshedpur 831007 , India \\ * Present Address: Institute of Metal Research, T.U. Berlin, Hardenbergstraße-36, D-10623, \\ Berlin, Germany \\ ** Materials Science Centre, Indian Institute of Technology, Kharagpur 721 302, India
}

\begin{abstract}
Stable magnetic powders, of 1-2 $\mu \mathrm{m}$ particle size, of partially Co-substituted, $\operatorname{Pr}_{2} \mathrm{Fe}_{14-x} \mathrm{Co}_{x} \mathrm{~B}, x \leqslant 3$, alloys together with $2-4$ at $\%$ excess $\operatorname{Pr}$ were prepared by rapidly quenching the associated melts into thin ribbons and then mechanical attriting the ribbons in the refined particle sizes. The saturation magnetization $M_{\mathrm{s}}$, remanent magnetization $J_{r}$, intrinsic coercivity $H_{\mathrm{ci}}$ and Curie temperature $T_{\mathrm{c}}$ were studied in characterizing the powders for fabricating into sintered or polymer bonded magnets. It is found that the small $x=0.4-0.8$ substitution of the $\mathrm{Co}$ on $\mathrm{Fe}$ sites in this series sensitively leads to an increase in the value of $H_{\mathrm{ci}}$, by as much as $40 \%$, with the optimum value of $21 \mathrm{kOe}$ at $x \sim 0.55$, together with an improvement in the $T_{\mathrm{c}}$ from $292^{\circ} \mathrm{C}$ to $325^{\circ} \mathrm{C}$, without significantly diluting the $M_{\mathrm{s}} \sim 150 \mathrm{emu} / \mathrm{g}$ and $J_{\mathrm{r}} \sim 8.0 \mathrm{kG}$ values. The Co-substituted $\operatorname{Pr}_{2} \mathrm{Fe}_{14} \mathrm{~B}$ alloy particles are better stable and corrosion resistant in ambient atmosphere. The results are discussed with the microstructure and comparison with the data for $\mathrm{Nd}_{2} \mathrm{Fe}_{14} \mathrm{~B}$ powders processed under the same conditions.
\end{abstract}

Keywords. Stable magnetic powders; $\mathrm{Pr}_{2} \mathrm{Fe}_{14-x} \mathrm{Co}_{x} \mathrm{~B}$.

\section{Introduction}

Since the discovery of $\mathrm{P4}_{2} / \mathrm{mnm}$ tetragonal $\mathrm{Nd}_{2} \mathrm{Fe}_{14} \mathrm{~B}$ phase as an excellent highenergy-density magnetic material (Herbst et al 1984; Buschow 1986), much research has been devoted to improve its stability with stable magnetic properties using different substitutions by different methods (Buschow 1986; Deruelle et al 1990; Lim et al 1991; Ram and Joubert 1992; Ram 1994, 1995; Ram et al 1995). 5-10 wt\% excess rare-earth $(\mathrm{R})$ in the $\mathrm{R}_{2} \mathrm{Fe}_{14} \mathrm{~B}$ series thus promptly stabilizes the hard magnetic phase with desired magnetic properties. It supports the high coercivity of the product and protects it against oxidation corrosion in ambient atmosphere, but adversely dilutes the total magnetic moment.

A high quality permanent magnet for high power dc motors, electricity generators, and other similar applications usually require a symmetric hysteresis loop with constant (and as high as possible) values of the saturation magnetization $M_{\mathrm{s}}$, remanent magnetization $J_{\mathrm{r}}\left(\right.$ or $B_{\mathrm{r}}$ ) and/or coercivity $H_{\mathrm{c}}$, which in turn result in a high value of the energy-product $(B H)_{\max }$, over a wide range of temperature of operation. In this respect, amongst the whole rare-earth $\mathrm{R}_{2} \mathrm{Fe}_{14} \mathrm{~B}$ series, the $\mathrm{Nd}$ and $\mathrm{Pr}$ based magnets are most widely applied. The intrinsic magnetic properties, i.e. the saturation magnetization $M_{\mathrm{s}}$, magnetocrystalline anisotropy $H_{\mathrm{a}}$ (or the anisotropy constants $K_{1}$ and $K_{2}$ ), or the Curie temperature $T_{c}$, of $\operatorname{Pr}_{2} \mathrm{Fe}_{14} \mathrm{~B}$ are very similar to those of $\mathrm{Nd}_{2} \mathrm{Fe}_{14} \mathrm{~B}$ (Buschow 1986). However, the neodymium is the most abundant and therefore the $\mathrm{Nd}-\mathrm{Fe}-\mathrm{B}$ alloys are less expensive and commercially easily available.

\footnotetext{
'Paper presented at the poster session of MRSI AGM VI, Kharagpur, 1995
} 
A disadvantage with the $\mathrm{Nd}_{2} \mathrm{Fe}_{14} \mathrm{~B}$ is that it is not uniaxial throughout its ferromagnetic range. Magnetic moments of the $\mathrm{Nd}$ and Fe atoms in the tetragonal $\mathrm{Nd}_{2} \mathrm{Fe}_{14} \mathrm{~B}$ crystal lattice are collinear with the easy axis of the magnetization (that is along the crystallographic c-axis) only over limited $T \geqslant T_{\mathrm{SR}}$ temperatures, and undergo spin-reorientation transitions at $T_{\mathrm{SR}}$, called the spin-reorientation transition temperature, distorting the hysteresis loop at lower temperatures (Givord et al 1986; Nishio et al 1990). This is ruled out in $\operatorname{Pr}_{2} \mathrm{Fe}_{14} \mathrm{~B}$, in which the $\mathrm{Pr}$ and $\mathrm{Fe}$ magnetic spins remain collinear along the c-axis up to $0 \mathrm{~K}$. This is discussed with the synthesis of stable $\operatorname{Pr}_{2+\delta} \mathrm{Fe}_{14} \mathrm{~B}$ powders, using a small 3-16at\% substitution of $\mathrm{Co}$ on the Fe sites together with an excess $(\delta \sim 0.538) \mathrm{Pr}$, with superior magnetic properties for practical applications as permanent magnets and other devices, in this article.

\section{Experimental}

The two series of polycrystalline alloys $\operatorname{Pr}_{2} \mathrm{Fe}_{14-x} \mathrm{Co}_{x} \mathrm{~B}(x \leqslant 3 \cdot 0)$ and $\mathrm{Nd}_{2} \mathrm{Fe}_{14-x} \mathrm{Co}_{x} \mathrm{~B}$ $(x \leqslant 3.0)$ were prepared by melting $99.9 \%$ pure ingots of the constituent elements at $\sim 1200^{\circ} \mathrm{C}$ in a boron nitride crucible by induction melting. Since the rare-earths $\operatorname{Pr}$ and $\mathrm{Nd}$ are somewhat volatile at this temperature, we started the reaction with $10-20 \%$ excess amounts of them over the $\mathrm{R}_{2} \mathrm{Fe}_{14} \mathrm{~B}$ phase. The boron content was maintained at stoichiometric level $\sim 6$ at $\%$ and the iron (cobalt) accounted for the balance. The recovered alloys were pulverized by a jaw crusher and a pin mill in an Ar atmosphere. 15-30 $\mu \mathrm{m}$ thin ribbons were melt-spun by ejecting the molten alloy on the surface of a rapidly spinning copper wheel under a pure Ar gas. Finally, the ribbons were cut, crushed and milled in fine powders of $1-2 \mu \mathrm{m}$ particle size, as discussed earlier (Ram 1995).

$X$-ray diffractogram, recorded using filtered Co-K $\alpha$ l radiation $(\lambda=0 \cdot 17903 \mathrm{~nm})$ on a Siemens Kristalloflex $X$-ray diffractometer, was used to characterize the formation of the primary ferromagnetic $\mathrm{R}_{2} \mathrm{Fe}_{14} \mathrm{~B}$ phase in the melt spun ribbons subsequent to thermal annealing between $500-700^{\circ} \mathrm{C}$, if necessary. The microstructures were studied with a JEOL 35 CF scanning electron microscope equipped with an X-ray detector for compositional analysis. Compositional maps of the primary phase showed $\mathrm{Fe} / \mathrm{Pr}$ (or $\mathrm{Nd}$ ) ratio varying between 6.8 and $7 \cdot 5$, which is very close to the ratio 14.2 in the $\mathrm{R}_{2} \mathrm{Fe}_{14} \mathrm{~B}$ structure.

The magnetic properties, i.e. the saturation magnetization $\left(M_{\mathrm{s}}\right)$, remanent magnetization $\left(J_{\mathrm{r}}\right)$ and intrinsic coercivity $\left(H_{\mathrm{ci}}\right)$, were measured using a vibrating sample magnetometer or a hysteresisgraph. The Curie temperature $\left(T_{\mathrm{c}}\right)$ was determined from thermomagnetogram, which was measured by heating the specimen (by a heating rate of $10^{\circ} \mathrm{C} / \mathrm{min}$ ) between 25 and $600^{\circ} \mathrm{C}$, at a magnetic field of $1-2 \mathrm{kOe}$, with a similar magnetometer in conjunction with a high temperature oven assembly to control and vary the temperature.

\section{Results and discussion}

\subsection{Microstructure, electron microprobe analysis and magnetic properties}

Scanning electron micrographs of the polycrystalline $\mathrm{R}-\mathrm{Fe}-\mathrm{B}$ samples exhibit platelet shaped particles of the ferromagnetic $\mathrm{R}_{2} \mathrm{Fe}_{14} \mathrm{~B}$ phase, with $\mathrm{R}$ for $\mathrm{Pr}$ or $\mathrm{Nd}$. In the 


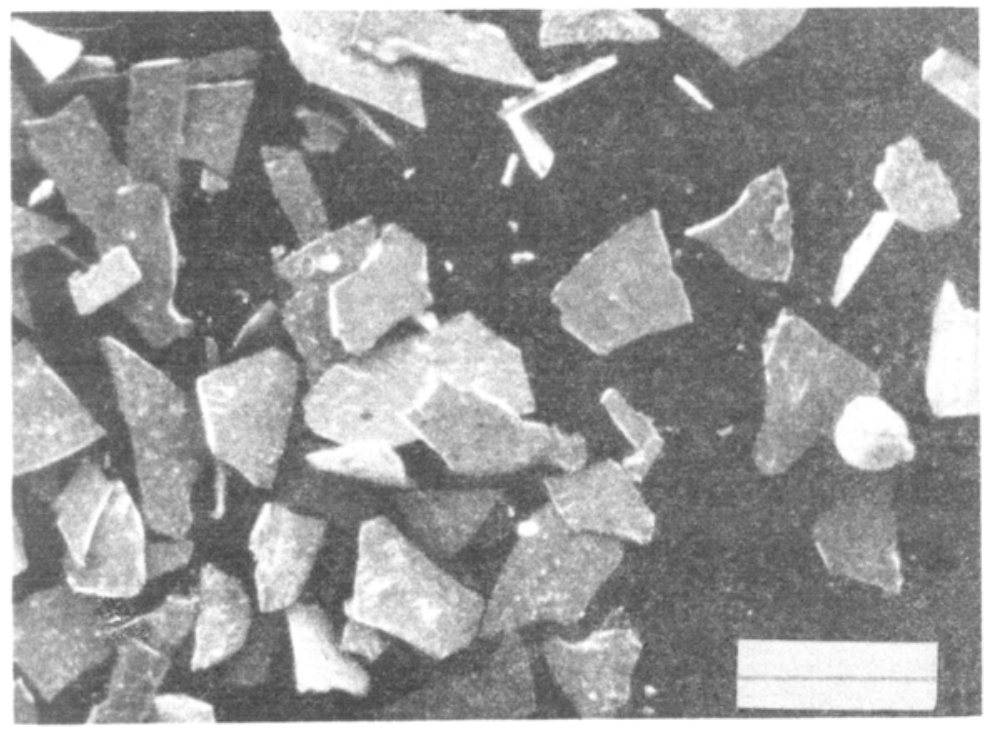

Figure 1. Scanning electron micrograph of a refined $\mathrm{Pr}-\mathrm{Fe}-\mathrm{B}$ powder of $1-2 \mu \mathrm{m}$ particle size. The scale bar refers to $2 \mu \mathrm{m}$.

Table 1. Magnetic properties of typical hot-pressed R-Fe-B alloys.

\begin{tabular}{lcccc}
\hline Composition & $\begin{array}{c}M_{\mathrm{s}} \\
(\mathrm{emu} / \mathrm{g})\end{array}$ & $\begin{array}{c}\mathrm{H}_{\mathrm{cj}} \\
(\mathrm{kOe})\end{array}$ & $\begin{array}{c}J_{\mathrm{t}} \\
(\mathrm{kG})\end{array}$ & $\begin{array}{c}T_{\mathrm{c}} \\
(\cdot \mathrm{C})\end{array}$ \\
\hline $\mathrm{Nd}_{12} \mathrm{Fe}_{82} \mathrm{~B}_{6}$ & 165 & 5 & 8.5 & 315 \\
$\mathrm{Nd}_{14.5} \mathrm{Fe}_{80} \mathrm{~B}_{5.5}$ & 163 & 25 & 7.5 & - \\
$\mathrm{Pr}_{14.5} \mathrm{Fe}_{80} \mathrm{~B}_{5.5}$ & 155 & 15 & 7.2 & 292 \\
$\mathrm{Nd}_{14.5} \mathrm{Fe}_{75} \mathrm{Co}_{5} \mathrm{~B}_{5.5}$ & 158 & 16 & 8.2 & 350 \\
$\operatorname{Pr}_{14.5} \mathrm{Fe}_{75} \mathrm{Co}_{5} \mathrm{~B}_{5 \cdot 5}$ & 153 & 18 & 8.0 & - \\
$\operatorname{Pr}_{14.5} \mathrm{Fe}_{76.9} \mathrm{Co}_{3.1} \mathrm{~B}_{5.5}$ & 154 & 21 & 8.1 & - \\
$\operatorname{Pr}_{15.5} \mathrm{Fe}_{63} \mathrm{CO}_{10} \mathrm{~B}_{5.5}$ & 150 & 17 & 7.8 & 429 \\
\hline
\end{tabular}

crystallized melt-spun ribbons, the particle size varies over a wide range between 1 and $50 \mu \mathrm{m}$, but those of milled in refined powder present a reasonably sharp size distribution in the range, $1-2 \mu \mathrm{m}$. For example, figure 1 shows a typical micrograph of a typical $\mathrm{Pr}-\mathrm{Fe}-\mathrm{B}$ alloy of final composition of $\operatorname{Pr}_{14.5} \mathrm{Fe}_{80} \mathrm{~B}_{5.5}$ (or $\operatorname{Pr}_{2+\delta} \mathrm{Fe}_{14} \mathrm{~B}$, with $\delta=0.538$ ), as analysed by the electron microprobe analysis. The final compositions of all the alloys studied here are summarized in table 1.

The saturation magnetization $M_{s}$, intrinsic coercivity $H_{\text {ci }}$, remanent magnetization $J_{r}$, and Curie temperature $T_{\mathrm{c}}$ of the samples are included in table 1. It is interesting to learn that small Co-substitutions $(x \leqslant 3)$ in the $\operatorname{Pr}_{2+\delta} \mathrm{Fe}_{14-x} \mathrm{Co}_{x} \mathrm{~B}$ series, having the $\delta=0.538$ excess $\operatorname{Pr}$, very sensitively leads to considerable improvement in the $H_{\mathrm{ci}}$ value (figure 2). For example, $x=0.2-0.8$ cobalt improves the $H_{\mathrm{ci}}$ by as much as $40 \%$ without significantly diluting the $M_{\mathrm{s}} \sim 150 \mathrm{emu} / \mathrm{g}$ or $J_{\mathrm{r}} \sim 8.0 \mathrm{kG}$ (figure 3) value. An optimum value of $H_{\mathrm{ci}}=21 \mathrm{kOe}$ (with $J_{\mathrm{r}}=8.1 \mathrm{kG}$ ) was thus found for the optimal composition of $x \sim 0.55$ at room temperature. The high $H_{\mathrm{ci}}$ value monotonically drops to the original Co free value at $x \sim 1.5$ and then almost linearly decreases as a function of $x$, basically governed 


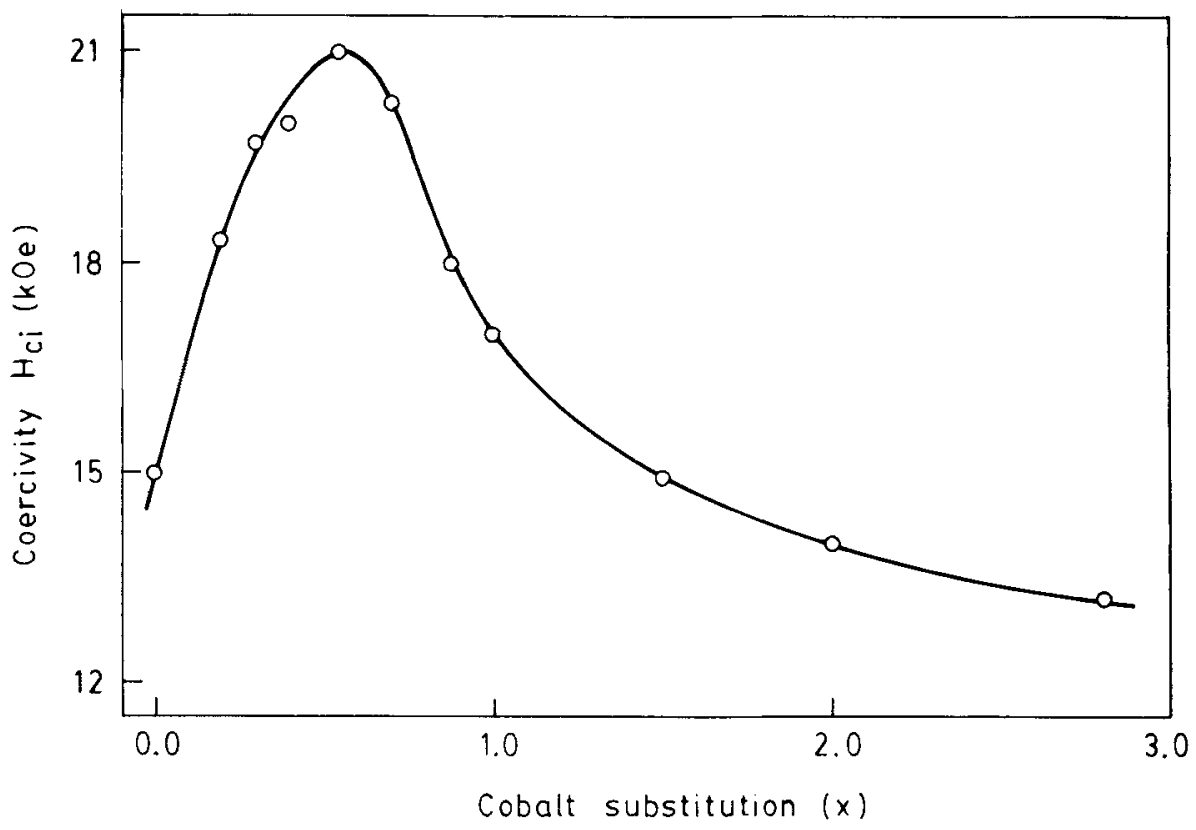

Figure 2. Effect of the cobalt substitution $(x)$ on coercivity $H_{\mathrm{ci}}$ in $\operatorname{Pr}_{2+\delta} \mathrm{Fe}_{14-x} \mathrm{Co}_{x} \mathrm{~B}$ powders.

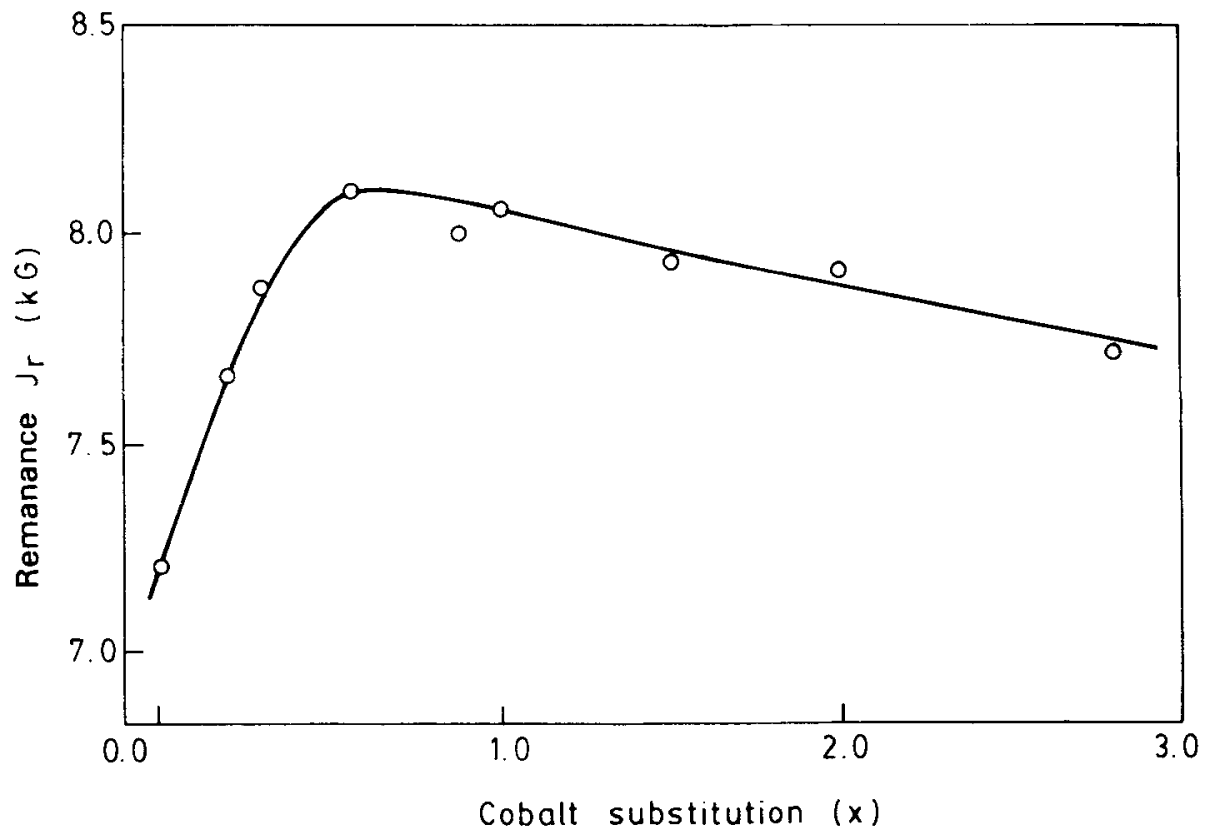

Figure 3. Effect of the cobalt substitution ( $x$ ) on remanent magnetization $J_{\mathrm{r}}$ in $\operatorname{Pr}_{2+\delta} \mathrm{Fe}_{14-x}$ $\mathrm{Co}_{x} \mathrm{~B}$ powders.

by the magnetocrystalline anisotropy $H_{\mathrm{a}}$, which is lowered by the effectively large Co-substitutions (Buschow 1986). We therefore selected a slightly larger $x \sim 3$ value, as the optimal Co-substitution, to improve the $T_{\mathrm{c}}$ as well and to balance a reasonably 
lowered temperature coefficient $\left(\partial M_{s} / \partial T\right)$ of the $M_{s}$ by the improved $T_{c}\left(\right.$ at $\left.429^{\circ} \mathrm{C}\right)$, suitable for applications as high-energy-density-magnets with steady $M_{\mathrm{s}}$ value over a wide range of temperature of operation at $70^{\circ} \mathrm{C}$ or lower. This composition $\left(\operatorname{Pr}_{15.5} \mathrm{Fe}_{63} \mathrm{Co}_{16} \mathrm{~B}_{5.5}\right)$, which in fact also has a marginally larger excess $\delta=0.71 \mathrm{Pr}$, yields the values of $M_{\mathrm{s}}=150 \mathrm{emu} / \mathrm{g}$, $H_{\mathrm{ci}}=17 \mathrm{kOe}$ and $J_{\mathrm{r}}=7.8 \mathrm{kG}$ at room temperature. The present $H_{\mathrm{ci}}=17 \mathrm{kOe}$ is significantly lower than the optimal value of $21 \mathrm{kOe}$, but it is stable and does not decrease further during storing the sample in the ambient atmosphere.

The cobalt substituted $\operatorname{Pr}_{2+\delta} \mathrm{Fe}_{14-x} \mathrm{Co}_{x} \mathrm{~B}, x \sim 3$, alloys behave to be better stable and corrosion resistant in air. As a result, the $\operatorname{Pr}_{15.5} \mathrm{Fe}_{63.0} \mathrm{Co}_{16.0} \mathrm{~B}_{5.5}$ alloy powder, which contains a total of $9 \mathrm{wt} \%$ excess $\mathrm{Pr}$ over the ideal $\mathrm{R}_{2} \mathrm{Fe}_{14} \mathrm{~B}$ composition, minimized the $M_{\mathrm{s}}$ loss at $5 \%\left(10 \%\right.$ in $\mathrm{Pr}_{2} \mathrm{Fe}_{14} \mathrm{~B}$ and $14 \%$ in $\left.\mathrm{Nd}_{2} \mathrm{Fe}_{14} \mathrm{~B}\right)$ in the presumed oxidation during exposure in laboratory air atmosphere. It exhibits a considerably enhanced $T_{\mathrm{c}}$ value from $292^{\circ} \mathrm{C}$ to $429^{\circ} \mathrm{C}$, determined by the thermomagnetogram (figure 4) measured at a constant magnetic field $H=1-2 \mathrm{kOe}$. The Co substitution causes a dramatic increase in $T_{\mathrm{c}}$ in both $\mathrm{Pr}_{2} \mathrm{Fe}_{14} \mathrm{~B}$ and $\mathrm{Nd}_{2} \mathrm{Fe}_{14} \mathrm{~B}$ alloys in similar fashion. In particular, $T_{\mathrm{c}}$ for $\mathrm{Pr}_{2} \mathrm{Fe}_{14} \mathrm{~B}\left(\mathrm{Nd}_{2} \mathrm{Fe}_{14} \mathrm{~B}\right)$ is $292^{\circ} \mathrm{C}\left(315^{\circ} \mathrm{C}\right)$, while $T_{\mathrm{c}} \sim 730^{\circ} \mathrm{C}$ for both $\mathrm{Pr}_{2} \mathrm{Co}_{14} \mathrm{~B}$ and $\mathrm{Nd}_{2} \mathrm{Co}_{14} \mathrm{~B}$.

This powder was used to fabricate into sintered or polymer bonded magnets. The die-upset powder at $40 \mathrm{kOe}$, measured on as high $J_{\mathrm{r}}$ as $13 \mathrm{kG}$, i.e. compatible to the value in Nd-based magnets. A special advantage with present magnets, over the Nd-based magnets, is that these can be used also at low temperatures (below $140 \mathrm{~K}$ ) because these are uniaxial up to $0 \mathrm{~K}$.

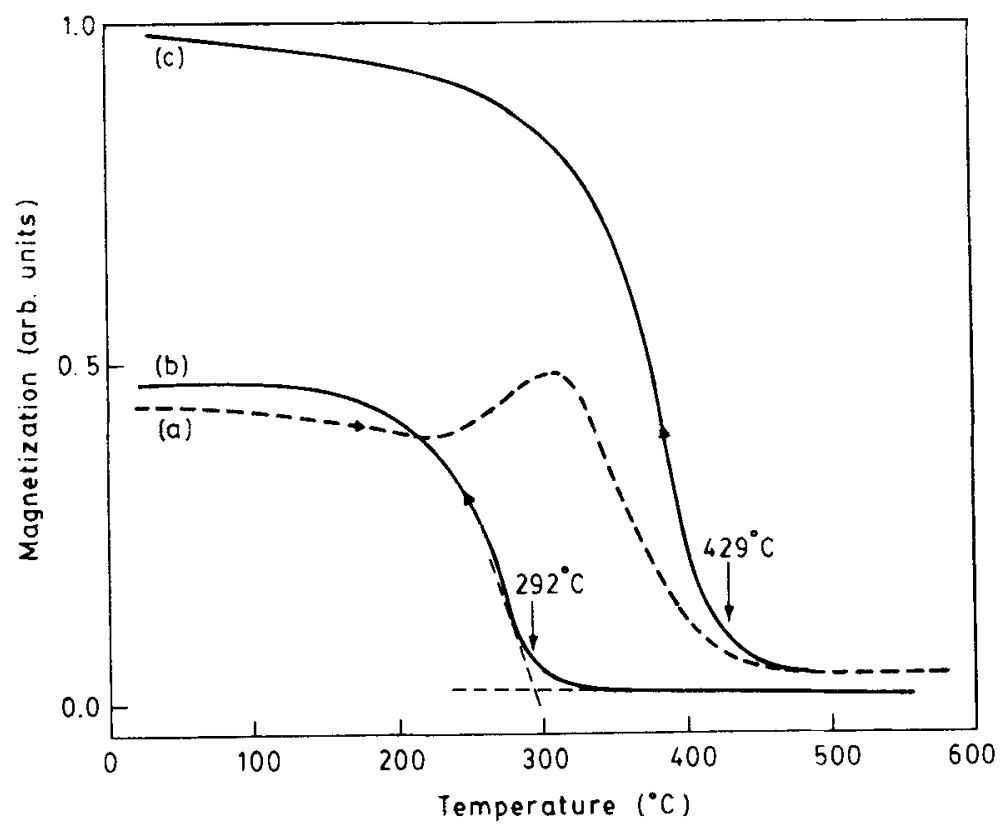

Figure 4. Thermomagnetograms of $\operatorname{Pr}_{15.5} \mathrm{Fe}_{63.0} \mathrm{Co}_{16.0} \mathrm{~B}_{5.5}$ powder measured at a magnetic field of $2 \mathrm{kOe}$. Curves (a) and (c) are measured during the heating and cooling, respectively. The $T_{\mathrm{c}}$ is significantly improved from $292^{\circ} \mathrm{C}$ in curve (b), measured in cooling cycle, to $429^{\circ} \mathrm{C}$ in curve (a) or (c) on the substitution of the cobalt. 


\subsection{Anomalous variation of $H_{c i}$ with temperature}

Figure 5 shows the value of $H_{\text {ci }}$ plotted as a function of temperature between 4.2 and $600 \mathrm{~K}$ for $\operatorname{Pr}_{14.5} \mathrm{Fe}_{80} \mathrm{~B}_{5.5}$ alloy. The obtained $H_{\mathrm{ci}}$ vs $T$ curve is eventually similar to that portrayed in figure 6 for a $\mathrm{Nd}$-based $\mathrm{Nd}_{14.5} \mathrm{Fe}_{76.9} \mathrm{Co}_{3.1} \mathrm{~B}_{5.5}$ alloy, which has a $H_{\mathrm{ci}}=17 \mathrm{kOe}$ value at room temperature. In both the examples, the $H_{\mathrm{ci}}$ value monotonically increases with decreasing temperature from $T=T_{\mathrm{c}}$ to $4.2 \mathrm{~K}$. This peculiar variation of $H_{\mathrm{ci}}$ with temperature is not well explained by available micromagnetic (Hilzinger and Kronmüller 1977; Kronmüller 1987; Kronmüller et al 1987) or pinning (Pinkerton and Fuerst 1990; Kou et al 1994) models.

According to the micromagnetic model (Kronmuller et al 1987), the value of $H_{\mathrm{ci}}$ is written as

$$
H_{\mathrm{ci}}=\left[\frac{2 K_{1}}{\mu_{0} M_{\mathrm{s}}}\right] a_{\mathrm{k}} a_{\phi}-N_{\mathrm{eff}} M_{\mathrm{s}},
$$

where $\mu_{0}, a_{\mathbf{k}}, a_{\phi}$ and $N_{\text {eff }}$ are the permeability, micromagnetic coefficient, microstructural coefficient, and the local demagnetization factor, respectively. In this model, the second order anisotropy constant $K_{2}$ is neglected in comparison to the first order anisotropy constant $K_{1}$. The parameters $a_{\mathbf{k}}$ and $a_{\phi}$ are the functions of temperature so that they account in the temperature dependence of the $H_{\mathrm{ci}}$ value.

In the hard ferromagnetic $\mathrm{R}-\mathrm{Fe}-\mathrm{B}$ alloys, having the microcrystals of $\mathrm{R}_{2} \mathrm{Fe}_{14} \mathrm{~B}$ as the primary phase, a high $H_{\mathrm{ci}}$ value usually results in the presence of a R-rich

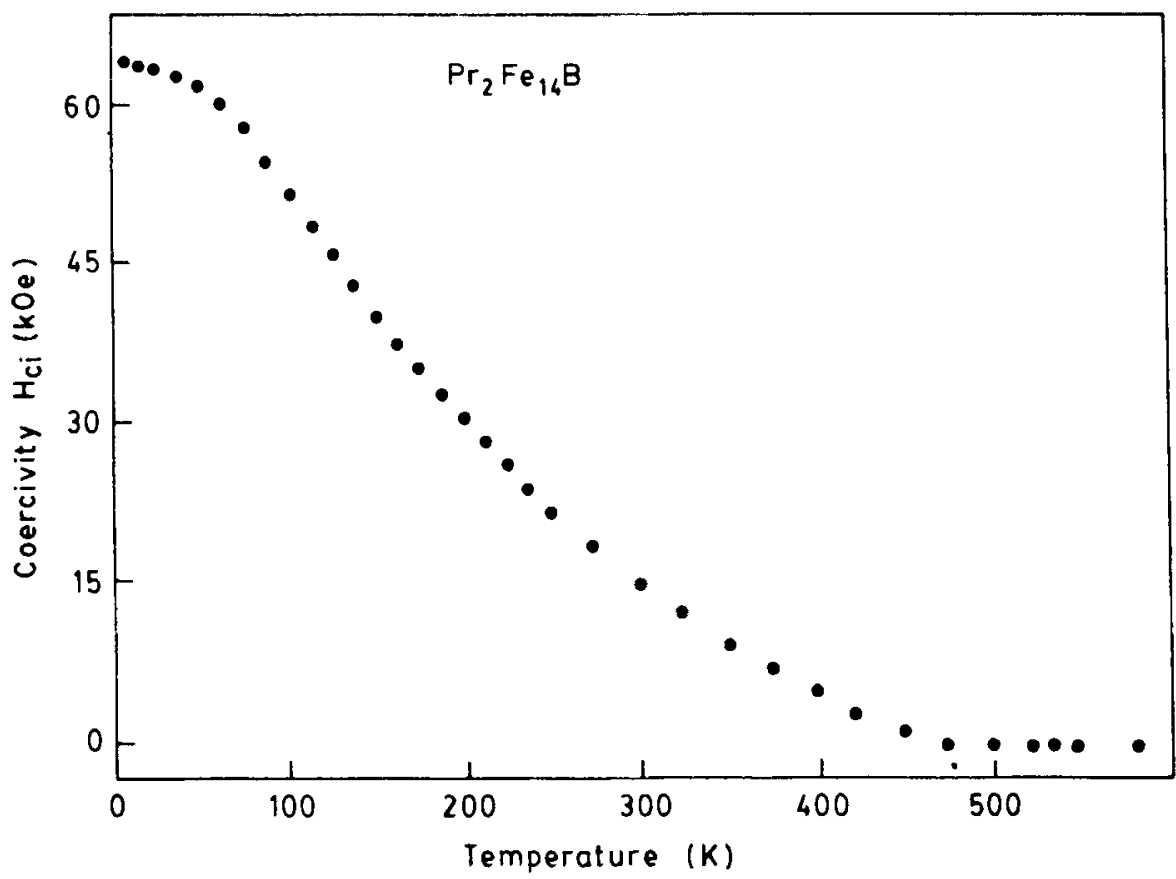

Figure 5. $H_{\mathrm{ci}}$ vs $T$ plot for $\operatorname{Pr}_{14.5} \mathrm{Fe}_{80} \mathrm{~B}_{5 \cdot 5}$ powder, which measures a $H_{\mathrm{ci}}=15 \mathrm{kOe}$ value at room temperature. 


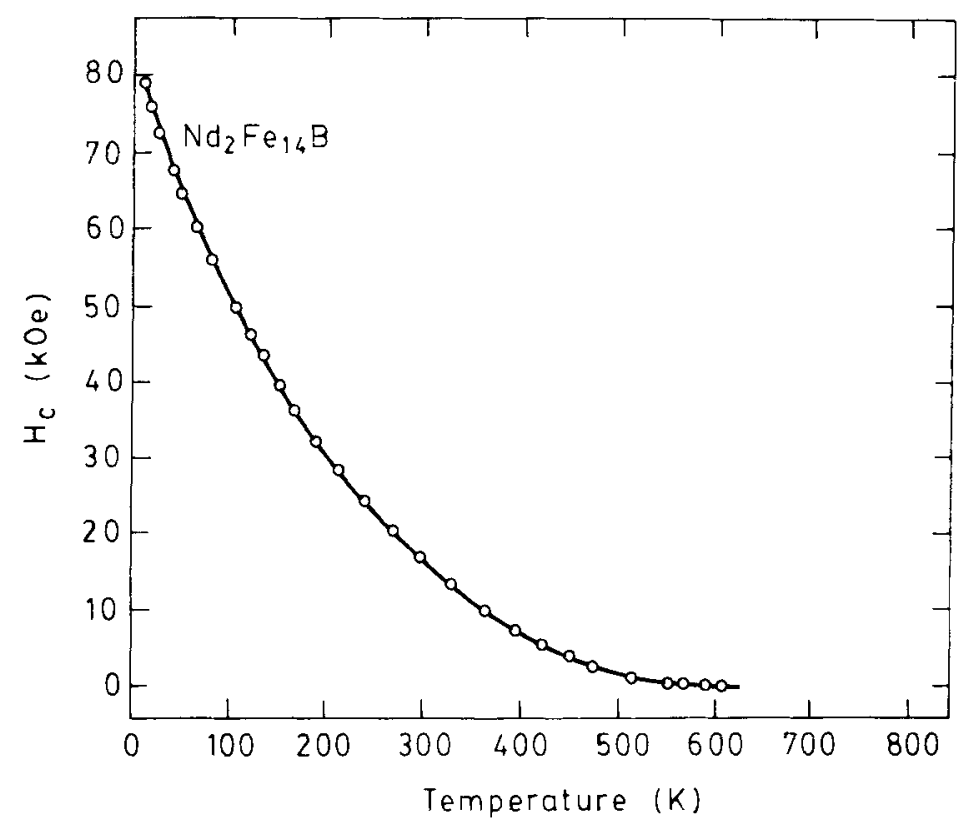

Figure 6. $H_{\mathrm{ci}}$ vs $T$ plot for $\mathrm{Nd}_{1+.5} \mathrm{Fe}_{7.6 .49} \mathrm{Co}_{3.1} \mathrm{~B}_{5.5}$ powder, which measures a $H_{\mathrm{ci}}=17 \mathrm{kOe}$ value at room temperature.

nonmagnetic intergranular phase (Pinkerton and Fuerst 1990). In the compositions, listed in table 1, the excess $\operatorname{Pr}$ (or Nd) forms the presumed R-rich intergranular phase with the $\mathrm{Fe}$ and/or $\mathrm{Co}$. That coats the ferromagnetic $(F) \mathrm{Pr}_{2} \mathrm{Fe}_{14} \mathrm{~B}$ grains by forming a thin layer, which is believed to be a few nanometer thick (Pinkerton and Fuerst 1990). Although it comprises of the magnetic atoms it surprisingly behaves to be nonmagnetic or possibly a diamagnetic $(D)$. It acts as pinning centres to prevent continuous motion of domain walls $(F)$ from grain to grain. In other words, it simply divides mixing of magnetic lines of forces of one grain to other. Therefore, they behave to be isolated single domain particles and consistently result in the enhanced $H_{\mathrm{ci}}$ value. The $D-F$ interaction (repulsion) is enhanced by the enhanced magnetic moments in the two phases at low temperatures so that the $H_{\mathrm{ci}}$ increases monotonically with decreasing the temperature.

In the absence of this intergranular phase, the domain walls run continuously from grain to grain, forming an extended domain structure, which continue through several grains. If we assume that the $\mathrm{R}_{2} \mathrm{Fe}_{14} \mathrm{~B}$ domain walls are pinned by thin intergranular layers, i.e. $\delta_{\mathrm{B}}>r_{0}$ (where $\delta_{\mathrm{B}}$ is the domain-wall width and $r_{0}$ the average half-width of the intergranular layer), $H_{\mathrm{ci}}$ is expressed by the relation (Kou et al 1994)

$$
H_{\mathrm{ci}}=(27)^{-1: 2}\left[\frac{2 \pi r_{0} k_{i}}{\mu_{0} \delta_{\mathrm{B}} M_{\mathrm{s}}}\right]-N_{\mathrm{eff}} M_{\mathrm{s}} .
$$

A comparison of the coefficients in relations (1) and (2) implies $a_{\mathrm{k}}=(27)^{-1 / 2} \pi r_{0} / \delta_{\mathrm{B}}$ and $a_{\phi}=1$. Moreover, if the $\mathrm{R}_{2} \mathrm{Fe}_{14} \mathrm{~B}$ domain walls are pinned by an extended planar 


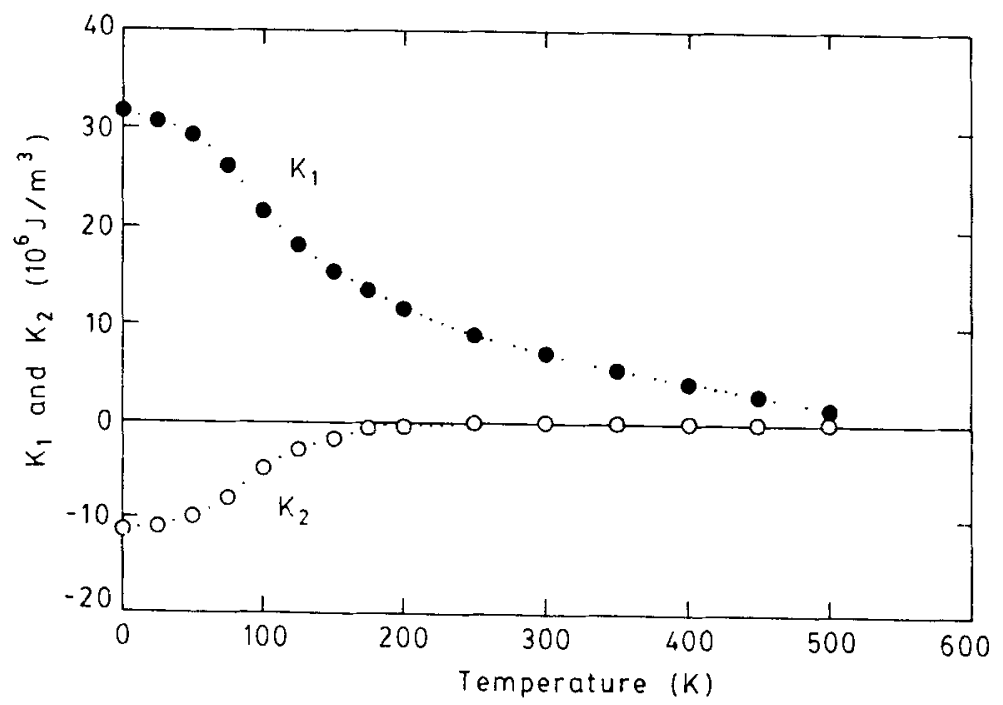

Figure 7. Variation of the anisotropy constants $K_{1}$ and $K_{2}$ with temperature in $\operatorname{Pr}_{2} \mathrm{Fe}_{14} \mathrm{~B}$ (after Kou et a! 1994).

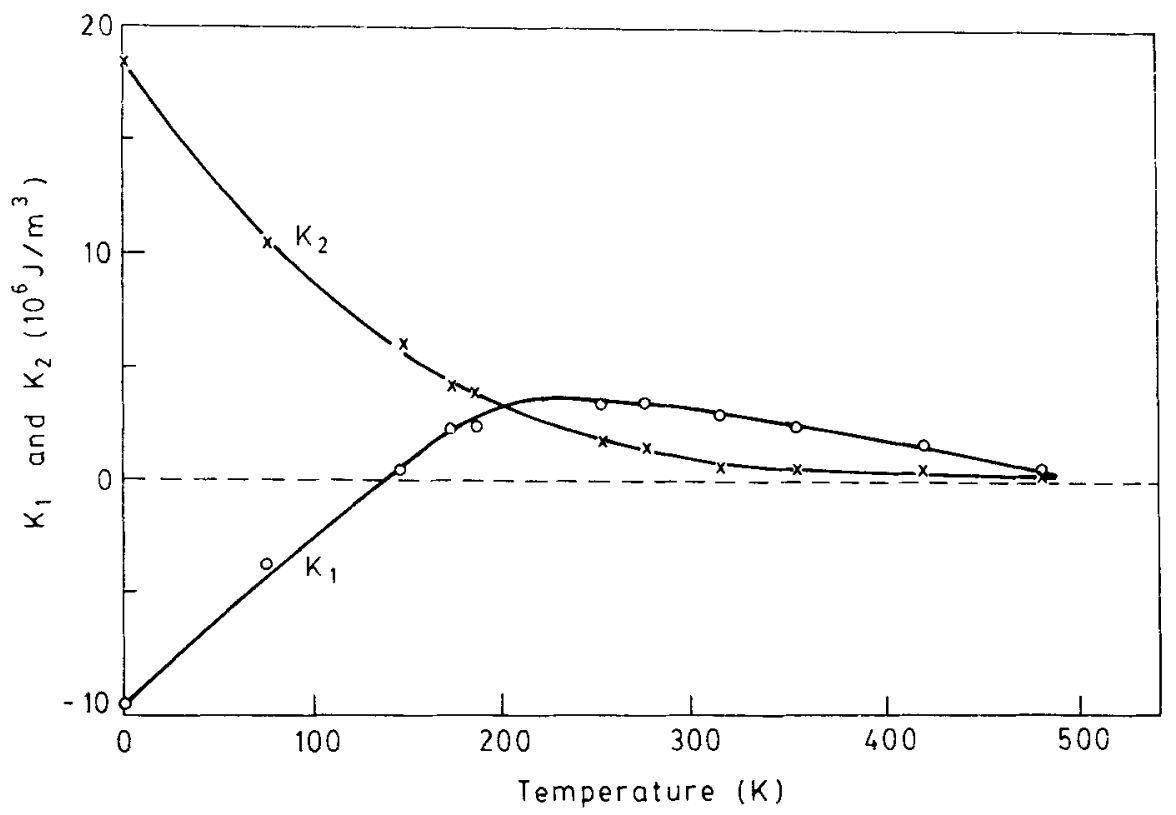

Figure 8. Variation of the anisotropy constants $K_{1}$ and $K_{2}$ with temperature in $\mathrm{Nd}_{2} \mathrm{Fe}_{14} \mathrm{~B}$ (after Yang et al 1985).

intergranular layer, i.e. $\delta_{\mathrm{B}}<r_{0}$, the above relation becomes (Kronmüller 1987)

$$
H_{\mathrm{ci}}=\left[\frac{4 \delta_{\mathrm{B}} K_{1}}{3 \pi \mu_{0} M_{\mathrm{s}} r_{0}}\right]-N_{\mathrm{eff}} M_{\mathrm{s}},
$$

which yields $a_{\mathrm{k}}=2 \delta_{\mathrm{B}} / 3 \pi r_{0}$ and $a_{\phi}=1$. 
Both of the above discussed models only indirectly involve the temperature dependent terms $a_{\mathrm{k}}, a_{\phi}, K_{1}$ and $K_{2}$. The $M_{s}$, which is a directly experimentally measured parameter, usually regularly increases in decreasing temperature in the $R_{2} F_{14} B$ ferromagnetic regime, and thus contributes an inversely proportionally decreasing value of $H_{\mathrm{ci}}$ as a function of temperature, but it is in an opposite trend to the observed variation of the effective $H_{\mathrm{ci}}$ value with temperature. It means that the other terms in the model play a more vital role in governing the viscosity of the high $H_{\mathrm{ci}}$ value. It is well established (Buschow 1986; Pinkerton and Fuerst 1990; Kou et al 1994) that a high $H_{\mathrm{ci}}$ value in $\mathrm{R}_{2} \mathrm{Fe}_{14} \mathrm{~B}$ alloys basically occurs due to the magnetocrystalline anisotropy $H_{\mathrm{a}}=2 K_{1} / \mu_{0} M_{\mathrm{s}}$, which defines the first term in the right hand side in relation (2) or (3). The value of $K_{1} \sim 31.5 \mathrm{MJ} / \mathrm{m}^{3}$ in $\mathrm{Pr}_{2} \mathrm{Fe}_{14} \mathrm{~B}$ at $0 \mathrm{~K}$ (see figure 7) is about 3 times larger than that in $\mathrm{Nd}_{2} \mathrm{Fe}_{14} \mathrm{~B}$ (see figure 8). Of course, in $\mathrm{Nd}_{2} \mathrm{Fe}_{14} \mathrm{~B}$, the value of $K_{1}$ is negative and $\sim 2$ times lower in magnitude than the value of $K_{2} \sim 18.2 \mathrm{MJ} / \mathrm{m}^{3}$ at $0 \mathrm{~K}$. It indicates that the first order anisotropy constant $K_{1}$ in $\operatorname{Pr}_{2} \mathrm{Fe}_{14} \mathrm{~B}$ and the second order anisotropy constant $K_{2}$ in $\mathrm{Nd}_{2} \mathrm{Fe}_{14}$ B prominently constitute the effective $H_{\text {ci }}$ value. Our $H_{\mathrm{ci}}$ vs $T$ curve for $\operatorname{Pr}_{2+\delta} \mathrm{Fe}_{14} \mathrm{~B}$, with $\delta=0.538$ alloy, in figure 5, thus qualitatively follows the $K_{1}$ vs $T$ curve portrayed in figure 7 . Likewise, the $H_{\mathrm{ci}}$ vs $T$ curve in figure 6 follows the $K_{2}$ vs $T$ curve in figure 8 in the Nd-based alloy. Obviously, a realistic model of $H_{\mathrm{ci}}$, which can account in the temperature dependence of it, must include both the anisotropy constants $K_{1}$ as well as $K_{2}$, and the magnetic viscosity caused by the interactions in the presence of the intergranular phases. Our further work in this series is in progress and the results will be communicated separately.

\subsection{Spin-reorientation transitions}

Our Pr-based alloys, unlike the Nd-based alloys. do not show any spin-reorientation transitions at temperatures below $T_{\mathrm{c}}$. In the $\mathrm{Nd}$-based alloys, the magnetization decreases with decreasing temperature below a certain value called the spin-reorientation transition temperature $T_{\mathrm{SR}}$. For example, figure 9 shows the thermomagnetograms of a typical sample recorded, between 300 and $4.2 \mathrm{~K}$, at two different magnetic fields of ( $\mathrm{a}$ and b) $10 \mathrm{kOe}$ and (c) $80 \mathrm{kOe}$. The total $M_{\mathrm{s}}$ (i.e. the saturation magnetization obtained in the high magnetic field scan of $80 \mathrm{kOe}$ ) clearly regularly decreases over low temperatures, effectively below $200^{\circ} \mathrm{C}$, with the onset temperature $T_{\text {md }}$ at $112 \mathrm{~K}$ (determined by the intersection of two straight lines in thermomagnetogram). A physical significance of $T_{\mathrm{md}}$ is that it defines a critical temperature below which the total $M_{\mathrm{s}}$ decreases with further decreasing the temperature, led by the spin-reorientations of the magnetic moments of the $\mathrm{Fe}$ and $\mathrm{Nd}$ atoms in the $\mathrm{Nd}_{2} \mathrm{Fe}_{14} \mathrm{~B}$ lattice. At $T \geqslant T_{\text {md }}$, the magnetic moments of both $\mathrm{Fe}$ and $\mathrm{Nd}$ atoms are collinear with the crystallographic c-axis in $\mathrm{Nd}_{2} \mathrm{Fe}_{14} \mathrm{~B}$ crystal lattice, but they undergo spin-reorientations at $T_{\mathrm{SR}}$, here $T_{\mathrm{SR}} \sim T_{\mathrm{md}}$, making a resultant angle $\theta_{\mathrm{c}}$ with the c-axis, which monotonically increases with further decreasing the temperature up to $T=0 \mathrm{~K}$ (Lim et al 1991).

It is interesting to note that the $\mathrm{Nd}_{2} \mathrm{Fe}_{14} \mathrm{~B}$ single crystals, which do not have any intergranular phase, do not exhibit so pronounced effects of the spin-reorientations on the total $M_{\mathrm{s}}$. The $M_{\mathrm{s}}$ value in this case regularly increases with the decreasing temperature, showing only a small change in the slope at $T_{\mathrm{SR}} \sim 126 \mathrm{~K}$ (Deruelle 1990). In fact, the presumed Nd-rich intergranular phase, which eventually behaves to be non-magnetic (or diamagnetic) compared to the ferromagnetic $\mathrm{Nd}_{2} \mathrm{Fe}_{14} \mathrm{~B}$, modifies 


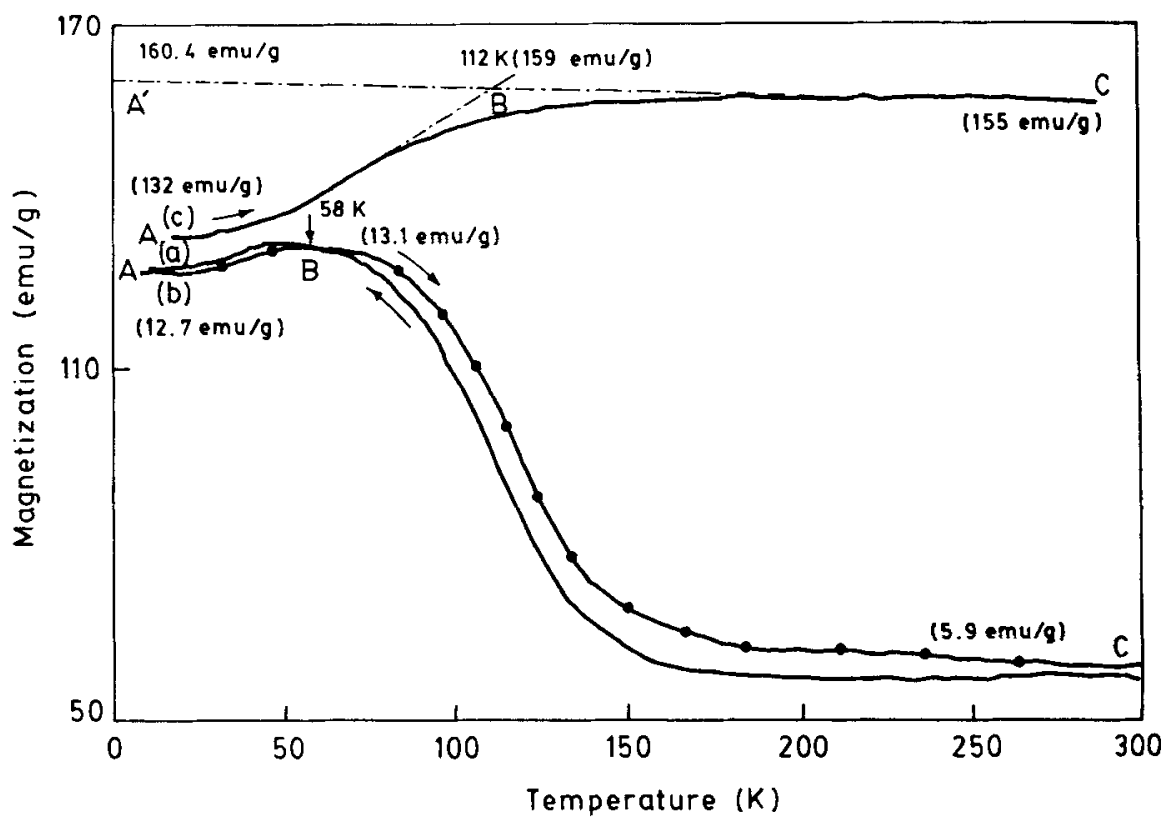

Figure 9. Thermomagnetograms of crystalline $\mathrm{Nd}_{15.5} \mathrm{Fe}_{03.0} \mathrm{Co}_{16.0} \mathrm{~B}_{5.5}$ powder recorded at (a) $10 \mathrm{kOe}$, (b) $10 \mathrm{kOe}$ and (c) $80 \mathrm{kOe}$. Curve (a) is measured in cooling cycle while curves (b) and (c) are measured in the heating cycles. The scale bar on the y-axis applies to curve (c). It is to be divided by a factor of 10 in the other curves.

the exchange interactions $\left(J_{\mathrm{FG}}\right)$, which are normally neglected (but appear peculiarly important in this particular example), between the ferromagnetic $\mathrm{Nd}_{2} \mathrm{Fe}_{14} \mathrm{~B}$ grains by inhibiting mixing of local magnetic lines of forces over isolated $\mathrm{Nd}_{2} \mathrm{Fe}_{14} \mathrm{~B}$ grains. The modified $J_{\mathrm{FG}}$, on the peculiarly modified $\mathrm{Nd}_{2} \mathrm{Fe}_{14}$ B grain-surfaces, eventually led to a modified and pronounced decrease of $M_{\mathrm{s}}$ with decreasing temperature over $T \leqslant T_{\mathrm{SR}}$.

Thus the total $M_{\mathrm{s}}$ of this binary (ferromagnetic $\mathrm{R}_{2} \mathrm{Fe}_{14} \mathrm{~B}$ and non-magnetic intergranular phase) magnetic phase material can be written as

$$
M_{\mathrm{s}}=(1-x) M_{\mathrm{s}}(F) \cos \theta_{\mathrm{c}}+x M(I),
$$

where $x$ is the fractional ratio of the intergranular phase of magnetic moment $M(I)$ and $M_{s}(F)$ is the magnetic moment of the ferromagnetic $\mathrm{Nd}_{2} \mathrm{Fe}_{14} \mathrm{~B}$ phase, which is modified by a factor of $\cos \theta_{\mathrm{c}}$ in the $T \leqslant T_{\text {md }}$ region, by the spin-reorientation transitions.

Relation (4) implies the value of $M(I)$ given by

$$
M(I)=-\left[\frac{(1-x) M_{\mathrm{s}}(F) \cos \theta_{\mathrm{c}}-M_{\mathrm{s}}}{x}\right],
$$

or

$$
M(I)=M_{\mathrm{s}}(F) \cos \theta_{\mathrm{c}}-\left(\frac{\Delta M_{\mathrm{FS}}}{x}\right),
$$

where $\Delta M_{\mathrm{FS}}=M_{\mathrm{s}}(F) \cos \theta_{\mathrm{c}}-M_{\mathrm{s}}$ is the contribution of the intergranular phase to the total magnetization. If we presume $M(I) \sim 0$, our experimental data in figure 9 
implies

and

$$
M_{\mathrm{s}}(F) \cos \theta_{\mathrm{c}}=\left(\frac{132}{1-x}\right)
$$

$$
M_{\mathrm{s}}(F)=\left(\frac{160 \cdot 4}{1-x}\right) \text {, }
$$

in emu/g at $4.2 \mathrm{~K}$, obtained by extrapolation of the straight line $\mathrm{CB}$ to point $\mathrm{A}$. On dividing relation (7) by relation (8), we get the value of $\cos \theta_{c}=1.82$, or $\theta_{c}=34.62^{\circ}$, which compares well with the resultant tilting angle (of the magnetic moments of the $\mathrm{Fe}$ and $\mathrm{Nd}$ atoms from the easy axis of the magnetization, i.e. along the crystallographic c-axis in the $\mathrm{P4}_{2} / \mathrm{mnm}$ tetragonal $\mathrm{Nd}_{2} \mathrm{Fe}_{14} \mathrm{~B}$ lattice) $\theta_{\mathrm{c}}=30^{\circ}$, as reported by magnetization measurements and torque measurements on single $\mathrm{Nd}_{2} \mathrm{Fe}_{14} \mathrm{~B}$ crystals by Tokuhara et al (1985).

Incorporating the experimental values of $M_{\mathrm{s}}(F)=195 \mathrm{emu} / \mathrm{g}$, for the single crystals $\left(\right.$ Ram 1995), and $\Delta M_{\mathrm{FS}}\left(=195 \cos \theta_{\mathrm{c}}-132\right)=28.47 \mathrm{emu} / \mathrm{g}$, at $4.2 \mathrm{~K}$, in relation (6), we obtain

$$
M(I)=160 \cdot 47-\left(\frac{28 \cdot 47}{x}\right),
$$

in $\mathrm{emu} / \mathrm{g}$ at $4.2 \mathrm{~K}$. It predicts a value of $M(I) \sim 0($ at $4 \cdot 2 \mathrm{~K})$ at $x \sim 0 \cdot 177$, and a negative value at a reasonably smaller $x$-value, which is not inadequate in this example.

The magnetic interaction between the two phases depends on (i) the spontaneous magnetization of the ferromagnetic phase, (ii) the field applied to magnetize the specimen, and (iii) the temperature during the measurement. At a given temperature $T \leqslant T_{\text {md }}$, where the concerned phase is strongly effective, the interaction indeed varies with applied field and the specimen responds differently at different magnetic fields. At effectively low fields of $10 \mathrm{kOe}$ or lower, it behaves as a soft magnetic material, with a reasonably low $H_{\mathrm{ci}}$ value, a low magnetization, and the magnetization peaks up (cf. curves 1 and 2 in figure 9) around $58 \mathrm{~K}$. The shape and size of the peak is reversible with respect to the heating and cooling the sample, but the position of the peak varies with the applied magnetic field, according to the competitive interactions developed between the internal fields in the presence of the applied magnetic field.

\section{Conclusions}

High coercivity stable magnetic powders (of $1-2 \mu \mathrm{m}$ particle size) of $\mathrm{Pr}-\mathrm{Fe}-\mathrm{B}$ alloys are developed using (i) a partial substitution (5-16 at \%) of cobalt on the $\mathrm{Fe}$ sites in the primary $\mathrm{P}_{2} / \mathrm{mnm}$ tetragonal $\mathrm{Pr}_{2} \mathrm{Fe}_{14} \mathrm{~B}$ ferromagnetic phase, and (ii) up to $\sim 3.5 \mathrm{at} \%$ excess $\mathrm{Pr}$ over to the ferromagnetic $\mathrm{Pr}_{2} \mathrm{Fe}_{14} \mathrm{~B}$ composition. The cobalt substitution, together with the excess $\operatorname{Pr}$, maintains a high value of $H_{\mathrm{ci}}=17 \mathrm{kOe}$, with reasonably increased Curie temperature from $292^{\circ} \mathrm{C}$ to $429^{\circ} \mathrm{C}$, useful for practical applications of the product as permanent magnets and related devices. The excess $\operatorname{Pr}$ with part of the cobalt forms highly corrosion resistant grain boundaries. As a result, the present powders behave to be better stable in the ambient atmosphere. 


\section{Acknowledgements}

The authors are thankful to Prof. $\mathrm{H} J$ Fecht, $\mathrm{T}$ U Berlin, Germany, for providing the laboratory facilities for some of the measurements. One of the authors $(\mathrm{SH})$ acknowledges the CSIR, India for the Junior Research Fellowship.

\section{References}

Buschow K J H 1986 Mater. Sci. Rep. 11

Deruelle M C D. Yamada M, Yamauchi H and Nakagawa Y 1990 Phys. Rev. B42 10291

Givord D, Tenau P and Viadieu T 1986 J. Appl. Phys. 603263

Herbst J F, Croat J J, Pinkerton F E and Yellon Y B 1984 Phys. Rev. B29 4176

Hilzinger H R and Kronmuller H 1977 Appl. Phys. 12253

Kou X C, Kronmuller H, Givord D and Rossignol M F 1994 Phys. Rev. B50 3849

Kronmüller H 1987 Phys. Status Solidi B144 385

Kronmüller H, Durst K D and Martinek G 1987 J. Magn. Magn. Mater. 6969

Lim D W, Kato H, Yamada M, Kido G and Nakagawa Y 1991 Phys. Rev. B44 10014

Nishio H, Yamamoto H, Nagakura M and Uehara M 1990 IEEE Trans. Magn. 26257

Pinkerton F E and Fuerst C D 1990 J. Magn. Magn. Mater. 89139

Ram S 1994 Phys. Rev. B49 9632

Ram S 1995 IEEE Trans. Magn. (to be published)

Ram S and Joubert J C 1992 J. Appl. Phys. 72 1164; and Appl. Phys. Lett. 61613

Ram S, Claude E and Joubert J C 1995 IEEE Trans. Magn. 30

Tokuhara K, Ohtsu Y, Ono F, Yamada O, Sagawa M and Matsuura Y 1985 Solid State Commun. 56333

Yang F M, Zhao X C, Zhao R W, Yu ZH and Zhang S G 1985 Proc. 4th int. symp. on magnetic anisotropy and coercivity in rare-earth-transition metal alloys (ed.) K Strnat (Dayton: Dayton Univ. Press) p. 529 